\title{
Diversidade genética de acessos do banco de germoplasma de mangaba em Sergipe
}

\author{
Tatiana Santos Costa ${ }^{(1)}$, Ana Veruska Cruz da Silva(2), Ana da Silva Lédo(2), \\ Allívia Rouse Ferreira dos Santos ${ }^{(3)}$ e Josué Francisco da Silva Júnior ${ }^{(2)}$
}

\begin{abstract}
(1)Universidade Federal de Sergipe, Núcleo de Pós-Graduação em Biotecnologia, Cidade Universitária Prof. José Aloísio de Campos, Avenida Marechal Rondon, s/non, Jardim Rosa Elze, CEP 49100-000 São Cristóvão, Sergipe. E-mail: tatiana_itase@hotmail.com (2)Embrapa Tabuleiros Costeiros, Avenida Beira Mar, № 3.250, CEP 49025-040 Aracaju, Sergipe. E-mail: anaveruska@cpatc.embrapa.br, analedo@cpatc.embrapa.br, josue@cpatc.embrapa.br (3)Universidad de Santiago de Compostela, Departamento de Producción Vegetal, Benigno Ledo, s/no, Lugo, 27.002, Galícia, Espanha. E-mail: alliviarouse@hotmail.com
\end{abstract}

Resumo - O objetivo deste trabalho foi estimar a variabilidade genética de acessos de mangaba provenientes de populações naturais, de 11 localidades, com marcadores RAPD. Os acessos pertencem ao Banco Ativo de Mangaba da Embrapa Tabuleiros Costeiros, em Itaporanga d'Ajuda, SE. Foram utilizados 13 iniciadores, que geraram 82 fragmentos, dos quais 78 (95\%) eram polimórficos. A análise genética entre localidades apresentou baixa diversidade genética; entretanto, a similaridade genética variou de 0,02 a 0,91 , para os 55 acessos. Foi possível identificar grupos divergentes por meio dos agrupamentos UPGMA e ACoP. Os acessos menos similares foram provenientes de Ipiranguinha (Conde, PB) e Preguiça (Indiaroba, SE), e os mais semelhantes de Jandaíra (Costa Azul, BA). Do conjunto total, 49 acessos foram geneticamente distintos e seis semelhantes. Por meio dos marcadores RAPD, foi possível obter um perfil molecular único, além de estimar a variabilidade existente entre os acessos avaliados. O Banco Ativo de Germoplasma de Mangaba da Embrapa Tabuleiros Costeiros apresenta baixa diversidade genética entre as localidades.

Termos para indexação: Hancornia speciosa, marcadores moleculares, recursos genéticos, variabilidade genética.

\section{Genetic diversity of accessions of the mangaba germplasm bank in Sergipe, Brazil}

\begin{abstract}
The objective of this work was to estimate the genetic variability of mangaba accessions of natural populations, from 11 locations, using RAPD markers. The accessions belong to Banco Ativo de Mangaba of Embrapa Tabuleiros Costeiros, in Itaporanga d'Ajuda, SE, Brazil. A total of 13 primers were used, which generated 82 fragments, of which 78 (95\%) were polymorphic. Genetic analysis among regions showed low genetic diversity; however, genetic similarity ranged from 0.02 to 0.91 , for the 55 accessions. Divergent groups were identified by UPGMA and ACoP clustering. The least similar accessions were derived from Ipiranguinha (Conde, PB, Brazil) and Preguiça (Indiaroba, SE, Brazil), and the most similar from Jandaíra (Costa Azul, BA, Brazil). From the total, 49 accessions were genetically distinct and six were similar. By using RAPD markers, it was possible to obtain a unique molecular profile, besides estimating the variability among the accessions evaluated. The Banco Ativo de Germoplasma de Mangaba of Embrapa Tabuleiros Costeiros shows low genetic diversity among locations.
\end{abstract}

Index terms: Hancornia speciosa, molecular markers, genetic resources, genetic variability.

\section{Introdução}

A mangabeira (Hancornia speciosa Gomes) é uma espécie frutífera e laticífera nativa do Brasil, da família Apocynaceae, que apresenta grande importância social, econômica e cultural nas áreas em que ocorre, sendo o Estado de Sergipe o maior produtor da fruta (Silva Júnior \& Lédo, 2006).

A produção dessa cultura é essencialmente extrativista e há poucos pomares organizados ou implantados para a exploração tecnificada (Ganga, 2008).
Típica de solos arenosos, ácidos e pobres em nutrientes, a mangabeira é encontrada na ampla vegetação do bioma do Cerrado, principalmente nas regiões Norte, Sudeste e Centro-Oeste e na região dos Tabuleiros Costeiros e da Baixada Litorânea (Vieira Neto et al., 2009).

Propagada por sementes, a mangabeira inicia sua produção entre o terceiro e o quinto ano após o plantio (Vieira Neto et al., 2009). Essa árvore de porte médio, de 2 a $10 \mathrm{~m}$ de altura, apresenta copa irregular e troncos tortuosos, ramificados e ásperos (Soares et al., 2007). 
As folhas são opostas, simples, pecioladas, glabras, brilhantes e coriáceas, de formato elíptico (Silva Júnior \& Lédo, 2006). As flores são hermafroditas, perfumadas, de coloração branca e apresentam um longo e estreito tubo floral com anteras localizadas na região apical; não são fundidas e são polinizadas por várias espécies de insetos lepidópteros (Darrault \& Schlindwein, 2005). O fruto é do tipo baga, elipsoide ou arredondado, com exocarpo amarelo. A polpa doce e com aroma agradável é bastante apreciada por seu sabor exótico característico, sua elevada acidez e seu alto conteúdo de sólidos solúveis. As sementes são recalcitrantes e podem ser semeadas até quatro dias após sua extração, pois logo diminuem sua atividade, ao sofrer desidratação em torno de 30\% (Soares et al., 2007).

Informações sobre o desenvolvimento e a variação genética de espécies nativas são fundamentais, já que a domesticação e a incorporação dessas espécies nos sistemas produtivos regionais, bem como o desenvolvimento de estratégias de conservação eficientes estão estreitamente relacionadas ao conhecimento da magnitude e da distribuição da variabilidade genética nas populações naturais.

Os Bancos Ativos de Germoplasma (BAGs) são uma alternativa para a conservação dos recursos genéticos vegetais. A avaliação da diversidade genética entre os acessos de um BAG resulta em informações sobre potenciais genitores a serem utilizados em programas de melhoramento; possibilita a identificação de duplicatas e o intercâmbio de germoplasma entre pesquisadores; e de acordo com Nass (2007), é uma forma de conciliar os esforços de conservação da agrobiodiversidade com o desenvolvimento sustentável. Assim, foi instalado, em 2006, na Embrapa Tabuleiros Costeiros, o Banco Ativo de Germoplasma de Mangaba (BGMangaba), em Itaporanga d'Ajuda, SE, que se tornou objeto de estudo permanente na área de recursos genéticos dessa espécie.

O conhecimento do grau de variabilidade genética, por meio de estudos de divergência, é fundamental no processo de identificação de novas fontes de genes de interesse (Falconer \& Mackay, 1996). Entre as formas para avaliar essa diversidade, destaca-se a caracterização molecular, que permite, a partir de marcas genéticas, indiferentes às interferências ambientais, inferir sobre o grau de diversidade entre indivíduos e entre populações.

Marcadores moleculares têm sido amplamente utilizados na caracterização de germoplasma, principalmente por fornecer informações sobre a variabilidade genética do DNA, ao eliminar possíveis efeitos ambientais (Castro et al., 2004; Chiorato et al., 2007). Para a constituição de variedades cultivadas, é necessário que haja diversidade genética suficiente para permitir a seleção de indivíduos que possam ser utilizados em programas de melhoramento. Portanto, o estudo dos componentes da variabilidade da espécie é fundamental, especialmente para espécies nativas pouco estudadas, cuja magnitude da diversidade ainda não é totalmente conhecida.

São raros os trabalhos sobre divergência genética de mangabeiras do Nordeste com uso de marcadores moleculares e morfológicos. Os primeiros iniciadores de RAPD, para a avaliação da estrutura genética de populações de $H$. speciosa do Cerrado, foram selecionados por Moura et al. (2005). Ganga (2008), ao estudar a variabilidade de plantas e progênies de populações nativas de $H$. speciosa no Cerrado, verificou elevado nível de variação fenotípica quanto aos caracteres de frutos e de crescimento. Moura et al. (2008), ao utilizar marcadores moleculares RAPD, observaram variação significativa entre $H$. speciosa var. pubescens e $H$. speciosa var. gardneri, tendo validado o uso de marcadores RAPD para o estudo da estrutura genética de populações de mangabeira.

O objetivo deste trabalho foi estimar a variabilidade genética de acessos de mangaba provenientes de populações naturais, de 11 localidades, com marcadores RAPD.

\section{Material e Métodos}

Foram utilizados acessos do BGMangaba, implantado em 2006, no Campo Experimental da Embrapa Tabuleiros Costeiros, em área de restinga, no Município

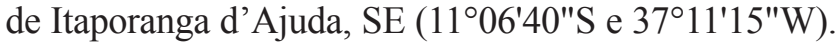
O banco é composto por 55 acessos, propagados por sementes, provenientes de 11 localidades diferentes. Os acessos foram coletados em áreas de ocorrência natural da mangabeira, nos estados da Bahia, Pará, Paraíba e Sergipe (Tabela 1).

Folhas jovens de cada acesso foram coletadas para extração de DNA; acondicionadas em gelo, para evitar oxidação; e transportadas para o Laboratório de Biologia Molecular da Embrapa Tabuleiros Costeiros, Aracaju, SE. As amostras foram mantidas em freezer a $-80^{\circ} \mathrm{C}$ até o momento da extração do DNA genômico. Cerca 
Tabela 1. Procedência dos 55 acessos do Banco Ativo de Germoplasma de Mangaba da Embrapa Tabuleiros Costeiros.

\begin{tabular}{|c|c|c|}
\hline Acesso & Local de coleta & Município \\
\hline PA1 & Paratibe & João Pessoa, PB \\
\hline PA2 & Paratibe & João Pessoa, PB \\
\hline PA3 & Paratibe & João Pessoa, PB \\
\hline PA4 & Paratibe & João Pessoa, PB \\
\hline PA5 & Paratibe & João Pessoa, PB \\
\hline GX2 & Guaxinduba & Conde, PB \\
\hline AD1 & Mata Redonda & Alhandra, PB \\
\hline AD2 & Mata Redonda & Alhandra, PB \\
\hline AD5 & Mata Redonda & Alhandra, PB \\
\hline AD6 & Mata Redonda & Alhandra, PB \\
\hline IP1 & Ipiranguinha & Conde, PB \\
\hline IP3 & Ipiranguinha & Conde, PB \\
\hline IP4 & Ipiranguinha & Conde, PB \\
\hline IP6 & Ipiranguinha & Conde, PB \\
\hline $\mathrm{AB} 1$ & Água Boa & Salvaterra, PA \\
\hline $\mathrm{AB} 2$ & Água Boa & Salvaterra, PA \\
\hline $\mathrm{AB} 3$ & Água Boa & Salvaterra, PA \\
\hline $\mathrm{AB} 4$ & Água Boa & Salvaterra, PA \\
\hline AB5 & Água Boa & Salvaterra, PA \\
\hline AB6 & Água Boa & Salvaterra, PA \\
\hline PT1 & Pontal & Indiaroba, SE \\
\hline PT2 & Pontal & Indiaroba, SE \\
\hline PT3 & Pontal & Indiaroba, SE \\
\hline PT4 & Pontal & Indiaroba, SE \\
\hline PT5 & Pontal & Indiaroba, SE \\
\hline PT6 & Pontal & Indiaroba, SE \\
\hline PR1 & Preguiça & Indiaroba, SE \\
\hline PR2 & Preguiça & Indiaroba, SE \\
\hline PR3 & Preguiça & Indiaroba, SE \\
\hline PR4 & Preguiça & Indiaroba, SE \\
\hline PR5 & Preguiça & Indiaroba, SE \\
\hline PR6 & Preguiça & Indiaroba, SE \\
\hline $\mathrm{TC} 1$ & Terra Caída & Indiaroba, SE \\
\hline $\mathrm{TC} 2$ & Terra Caída & Indiaroba, SE \\
\hline TC3 & Terra Caída & Indiaroba, SE \\
\hline $\mathrm{TC} 4$ & Terra Caída & Indiaroba, SE \\
\hline TC5 & Terra Caída & Indiaroba, SE \\
\hline TC6 & Terra Caída & Indiaroba, SE \\
\hline LG1 & Lagoa Grande & Mata de São João, BA \\
\hline LG2 & Lagoa Grande & Mata de São João, BA \\
\hline LG3 & Lagoa Grande & Mata de São João, BA \\
\hline LG4 & Lagoa Grande & Mata de São João, BA \\
\hline LG5 & Lagoa Grande & Mata de São João, BA \\
\hline LG6 & Lagoa Grande & Mata de São João, BA \\
\hline BI1 & Barra do Itariri & Conde, BA \\
\hline BI2 & Barra do Itariri & Conde, BA \\
\hline BI3 & Barra do Itariri & Conde, BA \\
\hline BI4 & Barra do Itariri & Conde, BA \\
\hline BI5 & Barra do Itariri & Conde, BA \\
\hline BI6 & Barra do Itariri & Conde, BA \\
\hline CA1 & Costa Azul & Jandaíra, BA \\
\hline CA2 & Costa Azul & Jandaíra, BA \\
\hline CA4 & Costa Azul & Jandaíra, BA \\
\hline CA5 & Costa Azul & Jandaíra, BA \\
\hline CA6 & Costa Azul & Jandaíra, BA \\
\hline
\end{tabular}

de $300 \mathrm{mg}$ de folhas foram maceradas em nitrogênio líquido, tendo-se adicionado, em seguida, $800 \mu \mathrm{L}$ de tampão de extração, de acordo com o método CTAB (2\% de CTAB - brometo de cetil trimetil amônio; EDTA - 0,5 M pH 8,0; Tris-Cl - $1 \mathrm{M} \mathrm{pH} \mathrm{8,0;} \mathrm{NaCl}$ 5M; e $2 \%$ de PVP) proposto por Doyle \& Doyle (1987), com modificações.

Cada reação de RAPD continha 50 ng de DNA, tampão de PCR com $\mathrm{MgCl}$ adicionado (Promega, Madison, South Dakota, EUA) 1X, dNTP $10 \mathrm{mmol} \mathrm{L}^{-1}$, 1,0 U de Taq DNA polimerase (Promega, Madison, South Dakota, EUA) e 3,0 ng de iniciador. Os DNAs foram amplificados com termociclador Biocycler (Hangzhou, Zhejiang, China), tendo sido submetidos a um ciclo inicial de desnaturação de $96^{\circ} \mathrm{C}$ por 5 min, seguido de 35 ciclos de $45 \mathrm{~s}$ a $94^{\circ} \mathrm{C}, 45 \mathrm{~s}$ a $36^{\circ} \mathrm{C}$, $45 \mathrm{~s}$ a $72^{\circ} \mathrm{C}$ e um ciclo de extensão final de $10 \mathrm{~min}$ a $72^{\circ} \mathrm{C}$. Foram testados 59 iniciadores de dez pares de base, dos quais 39 eram da marca Operon (Operon Technologies, Huntsville, Alabama, EUA) e 20 da marca IDT (Integrated DNA Technologies, Leuven, Bélgica).

$\mathrm{O}$ resultado da amplificação foi submetido à eletroforese horizontal, em gel de agarose a $1 \%$ e em tensão de $100 \mathrm{~V}$ por 1 hora. Após esse período, os géis foram postos em contato, em uma solução contendo brometo de etídio $\left(0,02 \mu \mathrm{L} \mathrm{mL}^{-1}\right.$ de água), por $30 \mathrm{~min}$, e visualizados sob luz ultravioleta. Para a mensuração do padrão dos fragmentos, foi utilizado o marcador de peso molecular de $1 \mathrm{~Kb}$, (Promega, Madison, South Dakota, EUA). A visualização dos resultados foi realizada em equipamento de fotodocumentação Gel doc L-pix (Loccus Biotecnologia, Cotia, SP).

O perfil eletroforético obtido para cada iniciador foi convertido em uma matriz binária, com base na presença (1) ou ausência (0) do fragmento. A percentagem de locos polimórficos, a amplitude dos fragmentos em pares de bases $(\mathrm{pb})$ e o número ótimo de fragmentos foram calculados com o auxílio do programa Genes (Cruz, 2006). A distribuição da variabilidade genética foi estimada para cada origem dos acessos, que foram analisados com o programa Genalex versão 6.3 (Peakall \& Smouse, 2006), tendo por base as seguintes variáveis: número total de alelos $(\mathrm{Na})$; número efetivo de alelos $(\mathrm{Ne})$; heterozigosidade esperada $(\mathrm{He})$; análise da variância molecular (AMOVA); e dissimilaridade genética de Nei (1978), calculada entre as localidades. A AMOVA foi realizada sem incluir a localidade 
Guaxinduba, por apresentar apenas um acesso (GX2), tendo-se utilizado 54 acessos e dez localidades, neste caso. Para todas as outras análises, foram utilizados os 55 acessos e as 11 localidades.

A distância genética foi obtida entre os pares de acessos pelo programa FreeTree (Pavlicek et al., 1999) de acordo com a similaridade do índice de Jaccard. Para as distâncias de Nei e Jaccard, foram calculados os erros associados à dissimilaridade e à similaridade, segundo Skroch et al. (1992), a 0,001\% de probabilidade. Os respectivos dendrogramas foram formados com base no agrupamento UPGMA ("unweighted pair group method using arithmetic averages"), que foi obtido pelo programa XLSTAT, para as diferentes localidades (Addinsolft, 2010), e pelo programa TreeView, entre os acessos (Page, 1996).

Para os 55 acessos, a consistência dos agrupamentos foi analisada por reamostragem "bootstrap", com o programa FreeTree (Pavlicek et al., 1999), a 10.000 x. O método de análise de coordenadas principais (ACoP) foi realizado com auxílio do XLSTAT (Addinsolft, 2010), para as diferentes localidades e para o total de acessos.

\section{Resultados e Discussão}

Dos 59 iniciadores testados, foram selecionados 13, considerados os mais eficientes, por apresentar fragmentos polimórficos nítidos. Foram amplificados 82 fragmentos, dos quais 78 (95\%) eram polimórficos (Tabela 2).
A partir das estimativas de correlação, observou-se uma relação diretamente proporcional entre o número de fragmentos analisados e a magnitude de correlação dos valores da matriz de similaridade original, obtida a partir de reamostragens com diferentes números de bandas (Figura 1). Houve consistência dos dados quando a correlação (r) atingiu 0,99 e o valor de estresse 0,04, em 75 fragmentos. Conforme Kruskal (1964), o número de bandas é considerado ideal quando o estresse apresenta valor inferior a 0,05 .

$\mathrm{O}$ número de bandas polimórficas variou de 1 (iniciador A5) a 24 (iniciador IDT 14), e a média foi de seis bandas por iniciador. Os iniciadores A11 (2.000 a $400 \mathrm{pb})$ e IDT 10 (750 a $250 \mathrm{pb})$ apresentaram maior e menor amplitude de pares de bases entre os fragmentos, respectivamente, e a média encontrada foi de $1.320 \mathrm{pb}$ (Tabela 2).

Os resultados de polimorfismo obtidos neste trabalho foram superiores aos relatados, na literatura, para o uso de marcadores moleculares RAPD na estimação da variabilidade de outras espécies. Castro et al. (2004), ao avaliar a divergência genética de acessos de mentrasto (Ageratum conyzoides L.), por meio de marcadores RAPD, obtiveram 26 bandas polimórficas, com 14 iniciadores. Silva et al. (2006), ao estudar a caracterização de acessos de melancia do BAG da Embrapa Semiárido, Petrolina, PE, com seis iniciadores, encontraram 64 bandas, das quais $31(48 \%)$ eram polimórficas. Chiorato et al. (2007), ao analisar a diversidade genética do banco de germoplasma de feijoeiro (Phaseolus vulgaris L.),

Tabela 2. Número e percentagem de bandas polimórficas por iniciador obtidos com marcadores RAPD em 55 acessos do Banco Ativo de Germoplasma de Mangaba da Embrapa Tabuleiros Costeiros.

\begin{tabular}{lcccc}
\hline Iniciador & Total de bandas amplificadas & Número de bandas polimórficas & Polimorfismo (\%) & Amplitude de pares de bases \\
\hline A2 & 5 & 4 & 80 & $1.300-250$ \\
A4 & 5 & 5 & 100 & $1.000-250$ \\
A5 & 1 & 1 & 100 & 600 \\
A11 & 4 & 4 & 100 & $2.000-400$ \\
B18 & 6 & 6 & 100 & $1.600-300$ \\
IDT 06 & 4 & 4 & 100 & $1.000-250$ \\
IDT 08 & 4 & 3 & 75 & $1.000-250$ \\
IDT 09 & 5 & 4 & 80 & $1.600-500$ \\
IDT 10 & 6 & 5 & 83 & $750-250$ \\
ITD 12 & 6 & 6 & 100 & $1.500-250$ \\
IDT 14 & 24 & 24 & 100 & - \\
S 18 & 6 & 6 & 100 & $2.000-750$ \\
W 04 & 6 & 6 & 100 & $1.500-500$ \\
Total & 82 & 78 & 95 &
\end{tabular}

Pesq. agropec. bras., Brasília, v.46, n.5, p.499-508, maio 2011 
verificaram $16 \%$ de polimorfismo, de 201 bandas, com uso de 19 iniciadores.

$\mathrm{O} \mathrm{Na}$ variou de 0,55 a 1,38 (Tabela 3), enquanto o Ne variou de 1,00 a 1,47. O índice de Shannon (I) variou de 0 a 0,38 (média de 0,25 ), e os valores de $\mathrm{He}$ variaram de 0 a 0,26 (média de 0,17 ). Esses parâmetros são fortemente influenciados pela deriva genética, já que alelos raros (com frequência inferior a 0,05 ) não são retidos. Entretanto, para inferir sobre a diversidade genética em uma população, é necessária uma análise comparativa entre os resultados, pois o valor de $\mathrm{Na}$ é mantido em longo prazo e o valor de He é influenciado pelo número de alelos e pela distribuição de suas frequências relativas (Raposo et al., 2007).

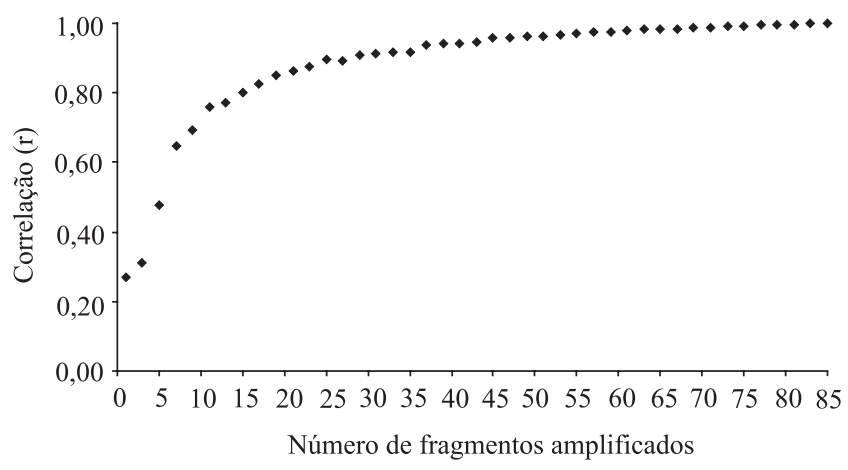

Figura 1. Coeficiente de correlação (r) e valor de estresse (E) a partir do número de fragmentos obtidos por marcadores RAPD para 55 acessos do Banco Ativo de Germoplasma de Mangaba da Embrapa Tabuleiros Costeiros.

Tabela 3. Número de acessos $(\mathrm{N})$, número total de alelos $(\mathrm{Na})$, número efetivo de alelos $(\mathrm{Ne})$, índice de Shannon (I) e heterozigosidade esperada (He), para as diferentes localidades de origem dos acessos do Banco Ativo de Germoplasma de Mangaba da Embrapa Tabuleiros Costeiros, obtidos por marcadores RAPD.

\begin{tabular}{lccccc}
\hline Local de coleta & $\mathrm{N}$ & $\mathrm{Na}$ & $\mathrm{Ne}$ & $\mathrm{I}$ & $\mathrm{He}$ \\
\hline Paratibe, PB & 5 & 1,08 & 1,29 & 0,24 & 0,16 \\
Guaxinduba, PB & 1 & 0,55 & 1,00 & 0,00 & 0,00 \\
Mata Redonda, PB & 4 & 1,13 & 1,33 & 0,27 & 0,19 \\
Ipiranguinha, PB & 4 & 1,05 & 1,27 & 0,25 & 0,16 \\
Água Boa, PA & 6 & 1,27 & 1,33 & 0,29 & 0,19 \\
Pontal, SE & 6 & 1,24 & 1,39 & 0,31 & 0,21 \\
Preguiça, SE & 6 & 1,38 & 1,46 & 0,38 & 0,26 \\
Terra Caída, SE & 6 & 1,25 & 1,31 & 0,27 & 0,18 \\
Lagoa Grande, BA & 6 & 1,33 & 1,33 & 0,28 & 0,19 \\
Barra do Itariri, BA & 6 & 1,36 & 1,35 & 0,29 & 0,20 \\
Costa Azul, BA & 5 & 0,99 & 1,19 & 0,15 & 0,11 \\
\hline Total & 55 & 1,15 & 1,29 & 0,25 & 0,17 \\
\hline
\end{tabular}

Os valores de $\mathrm{Na}$ obtidos para mangaba foram inferiores aos encontrados por Oliveira et al. (2008), que, ao estudar a variabilidade genética de fava d'anta (Dimorphandra mollis Benth), obtiveram valores de 1,7 para Na e 1,5 para Ne. Na literatura, há conhecimento de poucos trabalhos com marcadores RAPD relacionados a esse tipo de estudo, o que dificulta a comparação dos valores observados neste trabalho, com os encontrados em outras áreas ou bancos de germoplasma no país, para mangaba.

Para $\mathrm{He}$, os valores foram inferiores aos encontrados por Oliveira et al. (2008), em fava d'anta e em cajazeira (Spondias mombin L.) (Silva et al., 2009). O baixo valor de $\mathrm{He}(0,17)$ para os genótipos sugere uma baixa diversidade no BGMangaba. Em condições naturais, espera-se que a He seja sempre diferente de zero, pois há a possibilidade de os genótipos incorporarem novos alelos por meio de cruzamentos ou de ocorrer perdas em populações pequenas ou fragmentadas por deriva genética (Barreira et al., 2006).

O índice de Shannon é um identificador de diversidade, que varia entre 0 e 1 ; quanto mais próximo for de 1, mais diversa será a espécie (Perry \& McIntosh, 1991). Para a mangabeira, o valor médio desse índice foi de 0,25 , o que indica baixa diversidade entre as áreas de coleta - a localidade Preguiça (Indiaroba, $\mathrm{SE})$ apresentou o maior valor $(0,38)$. Esses valores podem ser atribuídos à fragmentação das áreas em que foram obtidos, com forte pressão de seleção antrópica. A comparação com o índice de Shannon encontrado em outros estudos é limitada, pois abordagens diferentes podem ter sido utilizadas para calculá-lo (Gillies et al., 1997). Assim, os resultados observados, neste trabalho, podem contribuir para grupos de pesquisa que utilizem padrões similares.

Por meio da AMOVA, observou-se que a variação molecular foi maior dentro das localidades $(66 \%)$ do que entre as origens dos acessos (34\%) (Tabela 4).

Tabela 4. Análise de variância molecular entre e dentro das diferentes localidades de origem dos acessos do Banco Ativo de Germoplasma de Mangaba da Embrapa Tabuleiros Costeiros.

\begin{tabular}{lccccc}
\hline Fonte de variação & GL & SQ & QM & Variância & CV (\%) \\
\hline Entre localidades & 9 & 335,37 & 37,26 & $5,17 * * *$ & 34 \\
Dentro das localidades & 43 & 426,70 & 9,92 & 9,92 & 66 \\
\hline Total & 52 & 762,07 & 47,48 & 15,10 & 100 \\
\hline
\end{tabular}

***Significativo a $0,1 \%$ de probabilidade 
A dissimilaridade, baseada na distância genética de Nei, calculada entre as localidades, variou de 0,11 $\pm 0,0$ (Mata Redonda, PB e Paratibe, PB) a 0,51 $\pm 0,5$ (Costa Azul, BA e Ipiranguinha, PB; Costa Azul, BA e Preguiça, SE). Os valores obtidos indicam o grau de dissimilaridade genética entre os acessos do BGMangaba $(0,44 \pm 0,05)$. $\mathrm{O}$ menor valor $(0,26 \pm 0,04)$ foi verificado entre os acessos provenientes da Paraíba, o que confirma a proximidade geográfica e genética.

Com base no dendrograma, houve diferenciação dos acessos a partir de 0,15 de dissimilaridade (Figura 2), o que indica baixa variabilidade genética entre as diferentes localidades de origem dos acessos do BGMangaba, como já proposto na análise da diversidade genética.

A partir da dissimilaridade genética média (DSGM - 0,14), houve a formação de dois grandes grupos: o primeiro foi composto por seis localidades (Mata Redonda, PB; Paratibe, PB; Água Boa, PA; Preguiça, SE; Ipiranguinha, PB; e Guaxinduba, PB), e o segundo por cinco (Barra do Itariri, BA; Lagoa Grande, BA; Pontal, SE; Terra Caída, SE; e Costa Azul, BA).

Para a ACoP, os dois primeiros componentes consolidaram 57 e 52\%, respectivamente, da variação total. Foram identificados cinco grupos entre as diferentes localidades dos acessos (Figura 3). O segundo grupo (II) foi composto por quatro

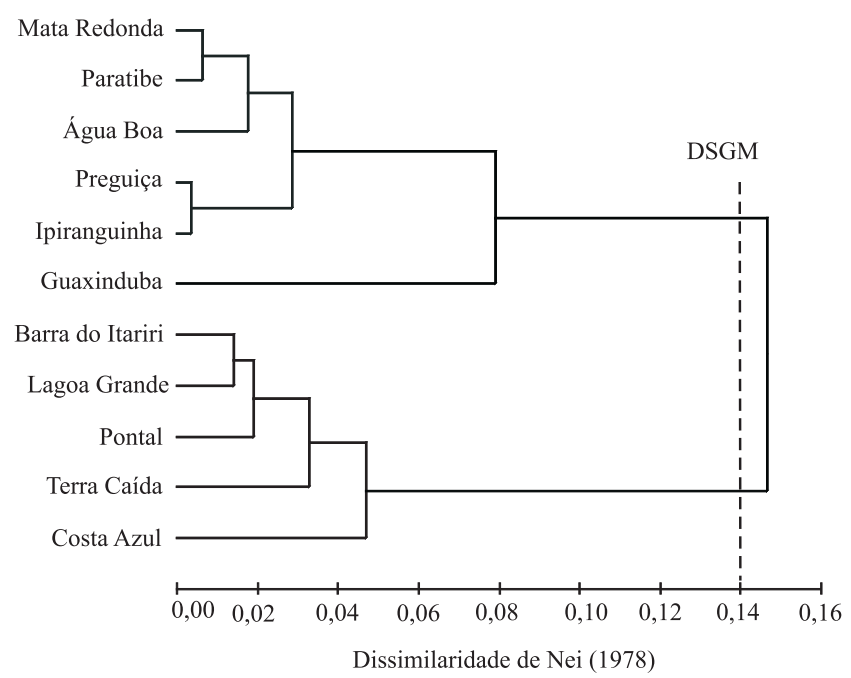

Figura 2. Representação filogenética pelo agrupamento UPGMA e dissimilaridade genética pelo coeficiente de Nei entre as diferentes localidades de origem dos acessos do Banco Ativo de Germoplasma de Mangaba da Embrapa Tabuleiros Costeiros. DSGM, dissimilaridade genética média. localidades (Mata Redonda, PB; Paratibe, PB; Água Boa, PA; e Pontal, SE); o terceiro (III) por duas (Ipiranguinha, PB e Preguiça, SE); e o quarto (IV) por três (Lagoa Grande, BA; Barra do Itariri, BA; e Terra Caída, SE). Costa Azul, BA, (V) e Guaxinduba, PB, (I) não se agruparam com outras localidades, tendo-se posicionado em quadrantes diferentes, o que indica maior diversidade genética para estes acessos.

Ao cruzar as informações entre o agrupamento UPGMA e a ACoP, observou-se que os grupos de acessos formados com origem em Mata Redonda, PB; Paratibe, PB; Água Boa, PA; e Pontal, SE, estão geneticamente relacionados. $\mathrm{O}$ mesmo ocorre para Ipiranguinha, PB, e Preguiça, SE. Apesar de ter um representante no BAG, Guaxinduba, PB, apresentou a maior diferença genética entre as localidades, pois se posicionou de maneira singular nos agrupamentos. As localidades delimitadas geograficamente entre Bahia e Sergipe, isto é, Lagoa Grande, BA; Barra do Itariri, BA; Terra Caída, SE; e Costa Azul, BA, não apresentaram essa barreira geográfica em relação à distância genética.

O emprego de mais de um método de agrupamento, em decorrência das diferenças na hierarquização, na otimização e na ordenação dos grupos, permite que a classificação se complemente em função dos critérios que cada técnica utiliza, além de impedir que inferências errôneas sejam adotadas na alocação de materiais, dentro de um determinado subgrupo de genótipos (Arriel et al., 2006).

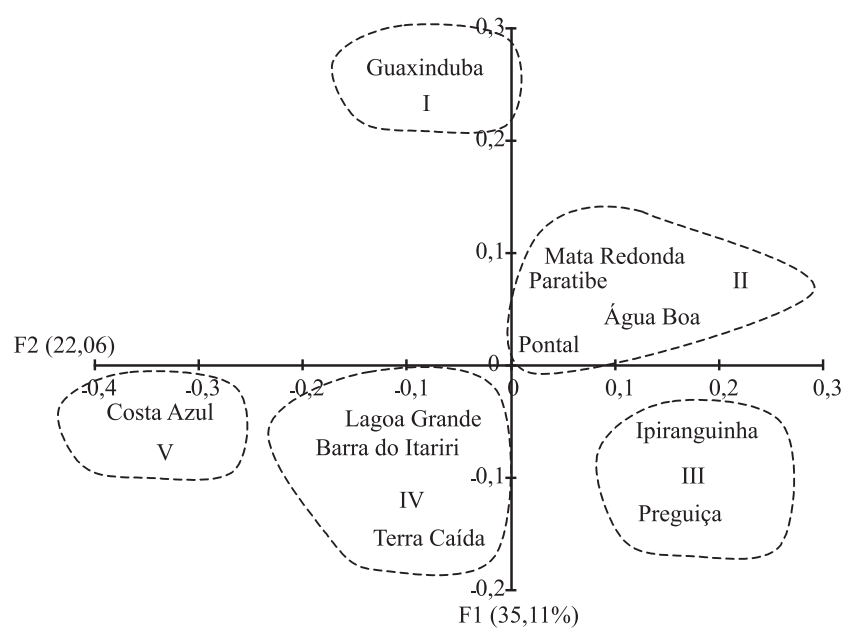

Figura 3. Análise de coordenadas principais (ACoP) para as diferentes localidades de origem dos acessos do Banco Ativo de Germoplasma de Mangaba da Embrapa Tabuleiros Costeiros. 
Para os dados relacionados à diversidade genética a similaridade média foi de $0,48(0,02-0,91)$, tendo entre acessos, obtidos com o coeficiente de Jaccard, variado de 0,02 $( \pm 0,05)$, para quatro pares de acessos

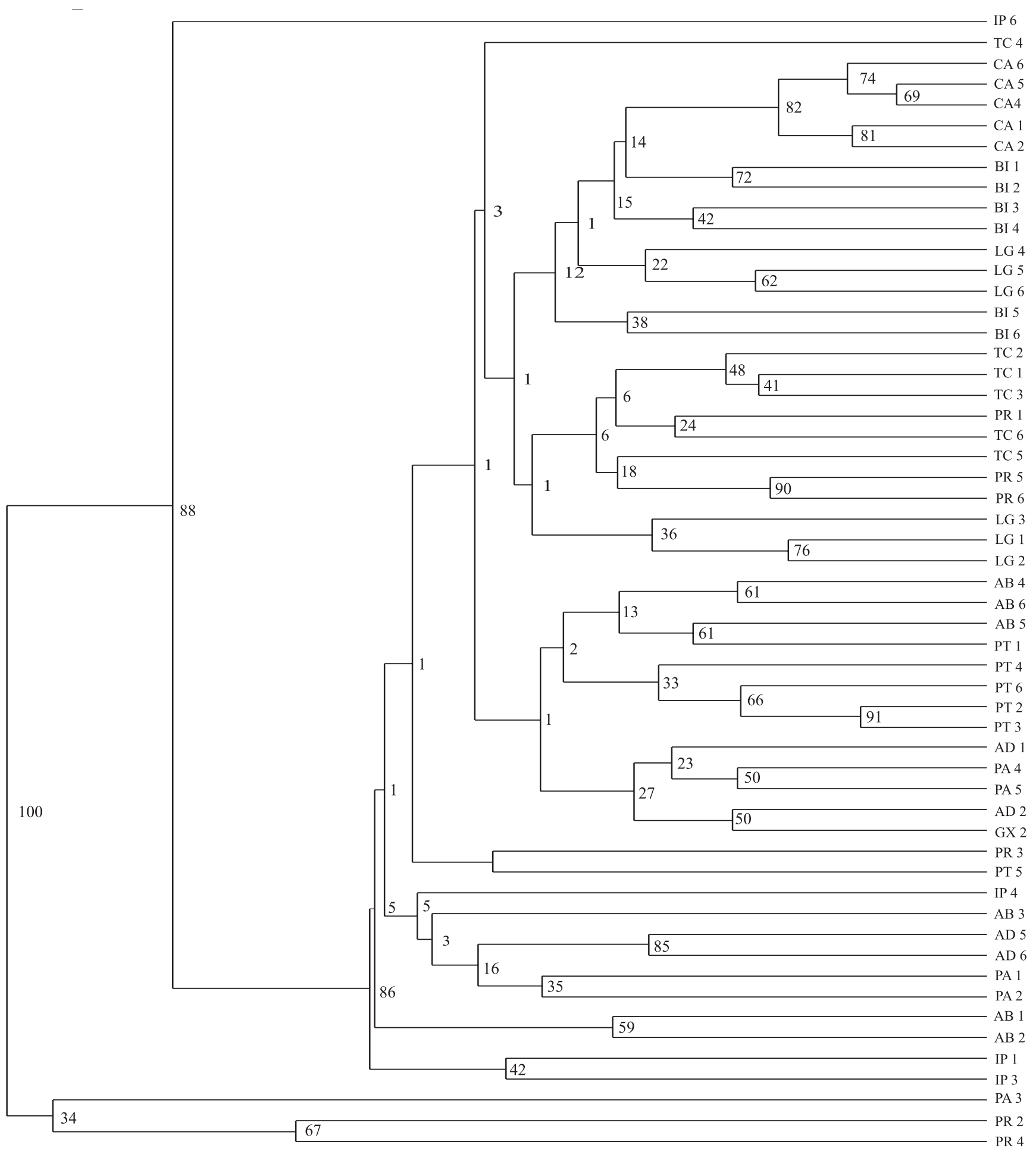

0,1

Figura 4. Representação filogenética pelo agrupamento UPGMA, similaridade genética pelo coeficiente de Jaccard (1908) e análise "bootstrap" (10.000 x) para 55 acessos do Banco Ativo de Germoplasma de Mangaba da Embrapa Tabuleiros Costeiros. SGM, similaridade genética média. 
(PR4 e AB3; TC6 e PR2; BI2 e PR4; e CA2 e PR4), coletados no Pará e em Sergipe, a 0,88 $( \pm 0,05)$, para PT2 e PT3, ambos de Sergipe. A partir do dendrograma (Figura 4), foi possível formar oito grupos. Os acessos que se destacaram foram o IP6 $(0,05)$ e o par de acessos PR2 e PR4 $(0,07 \pm 0,05)$, por serem mais divergentes; e o par de acessos PT2 e PT3 $(0,88 \pm 0,05)$, por serem mais similares.

Os grupos formados pelos acessos CA6 $(0,86)$, CA5 e CA4 $(0,91 \pm 0,05)$, CA1 e CA2 $(0,87 \pm 0,05)$, e PT2 e PT3 $(0,90 \pm 0,05)$ ficaram posicionados a partir do nível da similaridade genética média $(\mathrm{SGM})(0,83 \pm 0,05)$. Já que a SGM indica o valor acima do qual os indivíduos são considerados semelhantes, os pares apresentados podem ser considerados similares entre si.

Diferentemente dos dados obtidos neste trabalho, Chiorato et al. (2007), ao avaliar acessos de feijoeiro, obtiveram divergência genética de 0,13 a 0,82 . Junqueira et al. (2007), ao analisar a diversidade genética de acessos de maracujá-suspiro (Passiflora nitida Kunth.) verificaram valores de 0,03 a 0,61 , entre 19 acessos. Alves (2002) obteve valores de 0,02 a 0,99, entre acessos de cupuaçuzeiro [Theobroma grandiflorum (Willd. ex Spreng.) K. Schum.].

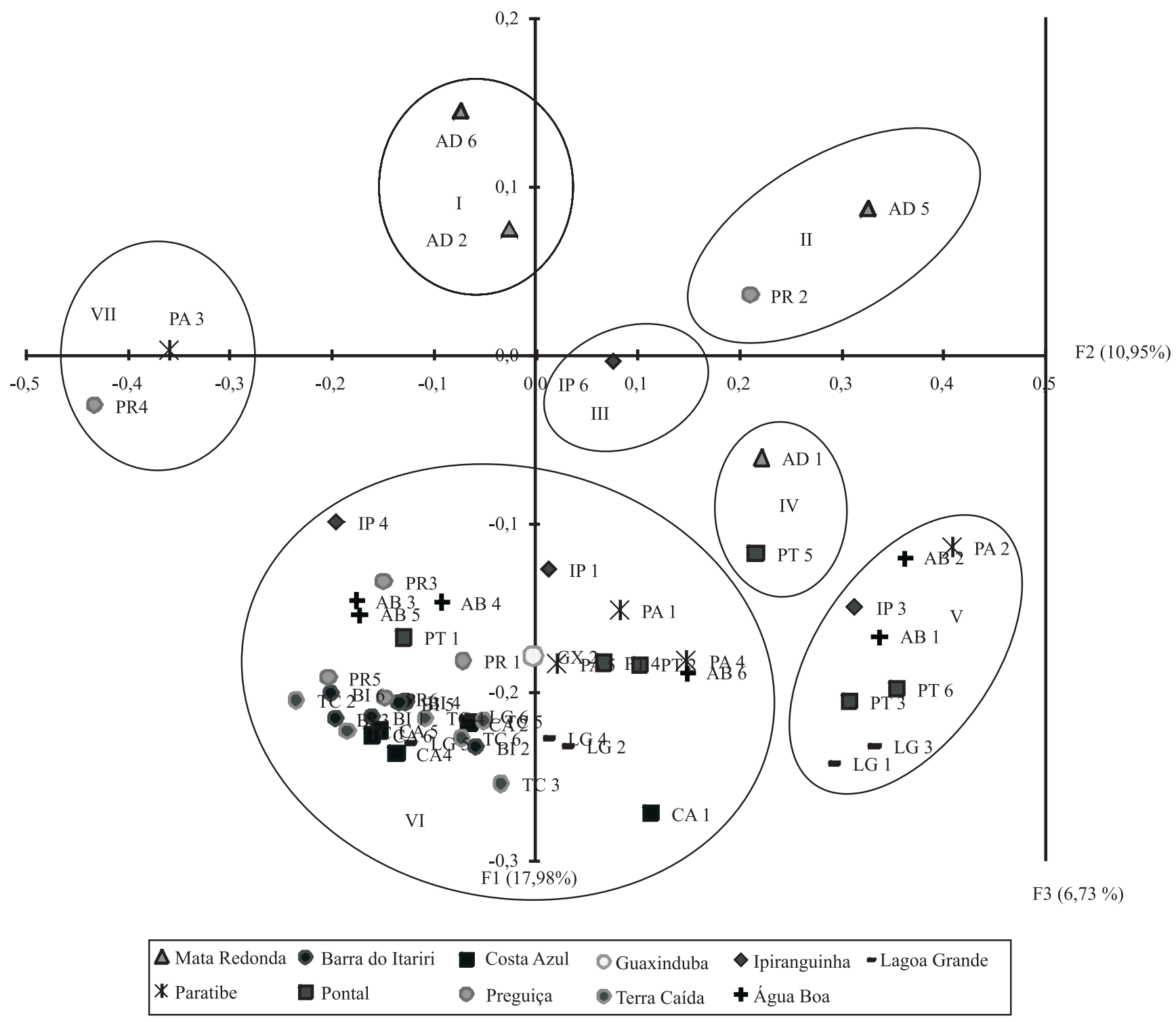

Figura 5. Análise de coordenadas principais (ACoP) para 55 acessos do Banco Ativo de Germoplasma de Mangaba da Embrapa Tabuleiros Costeiros. 
$\mathrm{Na}$ análise de agrupamento ACoP (Figura 5), os dois primeiros componentes principais apresentaram soma de variação de $28,93 \%$. Houve a formação de sete grupos: o primeiro (AD2 e AD6), o segundo (AD5 e PR2), o quarto (AD1 e PT5) e o sétimo grupo (PA3 e PR4) foram formados por apenas dois acessos; o quinto grupo apresentou oito acessos (PA2, AB2, IP3, AB1, PT6, PT3, LG3 e LG1), enquanto o sexto englobou grande parte das amostras, tendo apresentado 38 acessos, no conjunto. O acesso IP6 (terceiro grupo) não foi agrupado com os demais.

Ao analisar conjuntamente as informações entre o agrupamento UPGMA e a ACoP, observou-se que o acesso IP6 é o mais divergente, por estar isolado entre os agrupamentos. $\mathrm{O}$ grupo $\mathrm{V}$ da análise de coordenadas agrupou partes dos grupos G5, G6 e G7 do agrupamento UPGMA. Há um grande número de acessos agrupados no grupo VI da ACoP, similar ao maior número de acessos reunidos no dendrograma (G2 e G3), o que indica pouca divergência entre esses grupos. Os acessos AD6 e AD2 se agruparam em posições diferentes no dendrograma; contudo, na AcoP, ocorreu o contrário. O mesmo foi observado para os grupos I (AD6 e AD2), II (PR2 e AD5) e VII (PA3 e PR4) da ACoP. Todos os acessos provenientes de Terra Caída apresentaram-se ligados geneticamente, nos dois agrupamentos.

Por meio dos marcadores RAPD, foi possível obter um perfil molecular único, além de estimar a variabilidade existente entre os acessos avaliados. Para o total de acessos, os resultados indicam a existência de 49 acessos geneticamente distintos e seis semelhantes (CA4 e CA5; CA1 e CA2; e PT2 e PT3), no BGMangaba da Embrapa Tabuleiros Costeiros. Os resultados obtidos neste trabalho podem ser úteis em futuros programas de conservação e melhoramento desta espécie.

\section{Conclusões}

1. O Banco Ativo de Germoplasma de Mangaba da Embrapa Tabuleiros Costeiros apresenta baixa diversidade genética entre as localidades.

2. O conjunto de 55 acessos apresenta ampla distância genética, com 49 acessos distintos e seis geneticamente semelhantes.

3. Os pares de acessos CA4 e CA5; CA1 e CA2; e PT2 e PT3, provavelmente, são duplicatas.

\section{Referências}

ADDINSOLFT. XLSTAT statistical analysis software. Version 2010. Disponível em: <www.xlstat.com>. Acesso em: 25 mar. 2010.

ALVES, R.M. Caracterização genética de populações de cupuaçuzeiro, Theobroma grandiflorum (Wild. ex. Spreng.) Schum, por marcadores microssatélites e descritores botânico-agronômicos. 2002. 159p. Tese (Doutorado) - Escola Superior de Agricultura Luiz de Queiroz, Piracicaba.

ARRIEL, N.H.C.; DI MAURO, A.O.; DI MAURO, S.M.Z.; BAKKE, O.A.; UNÊDA-TREVISOLI, S.H.; COSTA, M.M.; CAPELOTO, A.; CORRADO, A.R. Técnicas multivariadas na determinação da diversidade genética em gergelim usando marcadores RAPD. Pesquisa Agropecuária Brasileira, v.41, p.801-809, 2006.

BARREIRA, S.; SEBBENN, A.M.; SCOLFORO, J.R.S.; KAGEYAMA, P.Y. Diversidade genética e sistema de reprodução em população nativa de Eremanthus erythropappus (DC.) MacLeish sob exploração. Scientia Forestalis, v.71, p.119-130, 2006.

CASTRO, H.G. de; SILVA, D.J.H. da; OLIVEIRA, L.O. de; FERREIRA, F.A.; SAKIYAMA, N.S.; BARBOSA, L.C. de A.; JÚNIOR, J.I.R. Diversidade genética entre acessos de mentrasto avaliados por características botânico-agronômicas, moleculares e fitoquímicas. Revista Ceres, v.51, p.227-241, 2004.

CHIORATO, A.F.; CARBONELL, S.A.M.; BENCHIMOL, L.L.; CHIAVEGATO, M.B.; DIAS, L.A. dos S.; COLOMBO, C.A. Genetic diversity in common bean accessions evaluated by means of morpho-agronomical and RAPD data. Scientia Agricola, v.64, p.256-262, 2007.

CRUZ, C.D. Programa GENES: análise multivariada e simulação. Viçosa: UFV, 2006. 175p.

DARRAULT, R.O.; SCHLINDWEIN, C. Limited fruit production in Hancornia speciosa (Apocynaceae) and pollination by nocturnal and diurnal insects. Biotropica, v.37, p.381-388, 2005.

DOYLE, J.J.; DOYLE, J.L. A rapid DNA isolation procedure for small quantities of fresh leaf tissue. Phytochemical Bulletin, v.19, p.11-15, 1987.

FALCONER, D.S.; MACKAY, T.F.C. Introduction to quantitative genetics. London: Longman, 1996. 464p.

GANGA, R.M.D. Variabilidade de plantas e progênies de populações naturais de Hancornia speciosa do Cerrado. 2008. 122p. Tese (Doutorado) - Universidade Federal de Goiás, Goiânia.

GILlIES, A.C.M.; CORNELIUS, J.P.; NEWTON, A.C.; NAVARRO, C.; HERNÁNDEZ, M.; WILSON, J. Genetic variation in Costa Rican populations of the tropical timber species Cedrela odorata L., assessed using RAPDs. Molecular Ecology, v.6, p.1133-1145, 1997.

JUNQUEIRA, K.P.; FALEIRO, F.G.; RAMOS, J.D.; BELLON, G.; JUNQUEIRA, N.T.V.; BRAGA, M.F. Variabilidade genética de acessos de maracujá-suspiro com base em marcadores moleculares. Revista Brasileira de Fruticultura, v.29, p.571-575, 2007.

KRUSKAL, J.B. Nonmetric multidimensional scaling: a numerical method. Psychometrika, v.29, p.115-129,1964. 
MOURA, N.F.; CHAVES, L.J.; VENCOVSKY, R.; ZUCCHI, M.I.; PINHEIRO, J.B.; MORAIS, L.K. de; MOURA, M.F. Seleção de marcadores RAPD para o estudo da estrutura genética de populações de Hancornia speciosa Gomez. Bioscience Journal, v.21, p.119-125, 2005.

MOURA, F.N.; MOURA, F.M.; PEREIRA, M.F.; NAVES, R.V.; CHAVES, J.L. Diversidade genética e variação fenotípica de caracteres morfológicos de mangabeira (Hancornia speciosa Gomes). In: SIMPÓSIO NACIONAL CERRADO, 9.; SIMPÓSIO INTERNACIONAL SAVANAS TROPICAIS, 2., 2008, Brasília. Desafios e estratégias para o equilíbrio entre sociedade, agronegócio e recursos naturais: anais. Planaltina: Embrapa Cerrados, 2008. p.1-7.

NEI, M. Estimation of average heterozygosity and genetic distance from a small number of individuals. Genetics, v.89, p.583-590, 1978.

NASS, L.L. Recursos genéticos vegetais. Brasília: Embrapa Recursos Genéticos e Biotecnologia, 2007. 858p.

OLIVEIRA, D.A. de; PAULA, M.F.B. de; PIMENTA, M.A.S.; BRAGA, R.F.; FERREIRA, M.F.M.; RODRIGUES, L.A. Variabilidade genética de populações de fava d'anta (Dimorphandra mollis) da região norte do Estado de Minas Gerais. Revista Árvore, v.32, p.355-363, 2008.

PAGE, R.D.M. TreeView: an application to display phylogenetic trees on personal computers. Computer Applications in the Biosciences, v.12, p.357-358, 1996.

PAVLICEK, A.; HRDA, S.; FLEGR, J. FreeTree-freeware program for construction of phylogenetic trees on the basis of distance data and bootstrap/jackknife analysis of the tree robustness. Application in the RAPD analysis of genus Frenkelia. Folia Biologica, v.45, p.97-99, 1999.

PEAKALL, R.; SMOUSE, P.E. GENALEX 6: genetic analysis in Excel. Population genetic software for teaching and research. Molecular Ecology Notes, v.6, p.288-295, 2006.
PERRY, M.C.; MCINTOSH, M.S. Geographical patterns of variation in the USDA soybean germplasm collection: I. Morphological traits. Crop Science, v.31, p.1350-1355, 1991.

RAPOSO, A.; MARTINS, K; CIAMPI, A.Y.; WADT, L.H. de O.; VEASEY, E.A. Diversidade genética de populações de andiroba no Baixo Acre. Pesquisa Agropecuária Brasileira, v.42, p.1291-1298, 2007.

SILVA JUNIOR, J.F. da; LÉDO, A. da S. (Ed.). Botânica. In: SILVA JUNIOR, J.F. da; LÉDO, A. da S. (Ed.). A cultura da mangaba. Aracaju: Embrapa Tabuleiros Costeiros, 2006. p.25-33.

SILVA, E.F. da; MARTINS, L.S.S.; OLIVEIRA, V.R. de. Diversity and genetic structure in cajá tree (Spondias mombin L.) populations in northeastern Brazil. Revista Brasileira de Fruticultura, v.31, p.171-181, 2009.

SILVA, M.L. da; QUEIRÓZ, M.A. de; FERREIRA, M.A.J. da F.; BUSO, G.S.C. Caracterização morfológica e molecular de acessos de melancia. Horticultura Brasileira, v.24, p.405-409. 2006.

SKROCH, P.W.; TIVANG, J.; NIENHUIS, J. Analysis of genetic relationships using RAPD marker data. In: SYMPOSIUM ON APPLICATIONS OF RAPD TECHNOLOGY TO PLANT BREEDING, 1992, Minneapolis. Proceedings. Minneapolis: Crop Science Society of America, 1992. p.26-30.

SOARES F.P.; PAIVA R.; CAMPOS, A.C.A.L.; PORTO, J.M.P.; NOGUEIRA R.C.; STEIN, V.C. Germinação de sementes de mangabeira (Hancornia speciosa Gomes) em diferentes substratos. Revista Brasileira de Biociências, v.5, p.1180-1182, 2007.

VIEIRA NETO, R.D.; SILVA JUNIOR, J.F. da; LEDO, A. da S. Mangaba. In: SANTOS-seREJO, J.A. dos; DANTAS, J.L.L.; COELHO, C.V.S.; COELHO, Y. da S. (Org.). Fruticultura tropical: espécies regionais e exóticas. Brasília: Embrapa Informação Tecnológica, 2009. p.323-338.

Recebido em 2 de outubro de 2010 e aprovado em 4 de abril de 2011 